\title{
A dual immunocytochemical assay for oestrogen and epidermal growth factor receptors in tumour cell lines
}

\author{
A. K. SHARMA ${ }^{1}$, K. HORGAN ${ }^{1 *}$, R. A. McCLELLAND ${ }^{2}$, A. G. DOUGLAS-JONES ${ }^{3}$, \\ T. VAN AGTHOVEN ${ }^{4}$, L. C. J. DORSSERS ${ }^{4}$ and R. I. NICHOLSON ${ }^{2}$ \\ ${ }^{1}$ Department of Surgery, University of Wales College of Medicine, Cardiff CF4 4XN, UK; ${ }^{2}$ Tenovus Cancer Research \\ Centre, University of Wales College of Medicine, Cardiff CF4 $4 X X, U K ;{ }^{3}$ Department of Pathology, University of Wales \\ College of Medicine, Cardiff CF4 $4 X N$, UK; and ${ }^{4}$ Department of Molecular Biology, Dr Daniel den Hoed Cancer Center, \\ 3008 AE Rotterdam, The Netherlands
}

Received 27 May 1993 and in revised form 5 August 1993

\begin{abstract}
Summary
A new dual immunocytochemical assay for oestrogen receptor (ER) and epidermal growth factor receptor (EGFR) has been developed. It has been tested in a variety of conditions using cell culture lines and the results correlate well with those obtained from single immunocytochemical assays.

MCF-7 and A43 I cells and a mixture of the two types of cell were assessed immunocytochemically for ER and EGFR. ER showed immunopositivity of $30 \%$ in MCF-7 cells, $10 \%$ in the mixture and $0 \%$ in A431 cells. EGFR demonstrated immunopositivity of $0 \%$ in MCF-7 cells, $70 \%$ in the mixture and $100 \%$ in A43I cells. Dual immunocytochemical assays using anti-ER followed by anti-EGFR monoclonal antibodies on single histological sections showed similar reactivity to the single assays. Three staining patterns were seen in the mixture: ER+/EGFR - (MCF-7 cells), ER-/EGFR - (MCF-7 cells) and ER-/EGFR+ (A431 cells). ZR-75-I and MDA-MB-231 cells and their retrovirally transfected counterparts ZR/HERc and MDA/HEGO cells were then analysed. The dual assay revealed the fourth phenotype (ER+/EGFR + ) in $40 \%$ of ZR/HERc cells and in $10 \%$ of MDA/HEGO cells.

This is the first description of a dual immunocytochemical assay system for ER and EGFR on single $5 \mu \mathrm{m}$ frozen section samples. Studies are now underway assessing breast carcinoma sections which may allow investigation of the clonality of human breast cancer.
\end{abstract}

\section{Introduction}

For over two decades, the evaluation of oestrogen receptor (ER) status in female breast cancer has been used to predict the response to hormonal therapy (Osborne et al., 1980). Initially the ER content was measured using biochemical ligand-binding assays of which the dextran-coated charcoal method was one of the most commonly-used examples (Sainsbury et al., 1985; Nicholson et al., 1986). However, these assays involved homogenization of the tissue samples and so did not allow investigation of receptor heterogeneity such as which cells were ER-positive (e.g. benign or malignant) or what proportion of cancer cells were ER-positive. The development of monoclonal antibodies specific for ER

*To whom correspondence and reprint requests should be sent. addressed these issues (King \& Greene, 1984) and a heterogeneous distribution consisting of ER-positive cells and ER-negative cells was demonstrated using an oestrogen receptor immunocytochemical assay (Walker et al., 1988).

More recently, the importance of epidermal growth factor receptor (EGFR) in human breast cancer has been established. EGFR is a high-affinity transmembrane glycoprotein with a molecular weight of 170000 (Cohen et al., 1982). It consists of an external ligand-binding domain (which contains a tyrosine-specific protein kinase) (Downward et al., 1984). EGFR presence in human female breast cancer has been found to be associated with poor response rates to endocrine therapy and reduced relapse-free and overall survival (Nicholson et al., 1990). Again initial studies involved biochemical ligand-binding assays but the development of a monoclonal antibody 
against EGFR in the epidermoid cancer line A43I (EGFR1) which has a high EGFR content (Waterfield et al., 1982) has allowed EGFR immunolocalization in frozen section samples.

Both biochemical ligand-binding and immunocytochemical assays have revealed a strong inverse relationship between ER and EGFR with most breast cancers being either ER-positive/EGFR-negative or ERnegative/EGFR-positive (Sainsbury et al., 1985, 1987; Lewis et al., 1990). However, a small proportion ranging from $4 \%$ (Bilous et al., 1992) to $37 \%$ (Bevilacqua et al., 1990) of primary breast cancers are positive for both receptors by immunocytochemical analysis. Attempts have been made to see if individual cancer cells within this group can express both ER and EGFR by using immunocytochemical assays on serial 4 to $6 \mu \mathrm{m}$-thick frozen sections (Toi et al., 1989). The results seem to suggest that ER and EGFR expression are mutually exclusive within an individual cancer cell. However, with serial sections there is no guarantee that the same cell or cell groups are being examined in different sections.

The aims of the present study were, thus, twofold. Firstly, to develop a dual immunocytochemical assay, comparable to single assays of proven prognostic significance (McClelland et al., 1986; Lewis et al., 1990), capable of detecting both ER and EGFR on a single 5- $\mu$ m frozen section sample. Secondly, to ascertain whether individual cancer cells could co-express, or be constructed to co-express, both ER and EGFR.

\section{Materials and methods}

\section{Materials}

Three flasks of the human breast cancer cell line MCF-7 were cultured simultaneously in RPMI 1640 medium (Gibco BRL, Life Technologies Ltd, Paisley, UK) and $10 \%$ fetal calf serum (FCS) in a humidified incubator with $5 \% \mathrm{CO}_{2}$ at $37^{\circ} \mathrm{C}$ for 2 weeks. They were harvested prior to confluence. Three flasks of the epidermoid cancer cell line A43I were also cultured simultaneously in Dulbecco's modified Eagle's medium (DMEM) from Gibco and 10\% FCS in a humidified incubator with $5 \% \mathrm{CO}_{2}$ at $37^{\circ} \mathrm{C}$ for 1 week. ZR-75-1, ZR/HERc, MDA-MB-23I and MDA/HEGO cells were maintained in RPMI-1640 medium supplemented with $10 \%$ heat-inactivated bovine calf serum (HyClone Laboratories Inc. Logan, UT, USA). The culture medium of ZR-75-I and ZR/HERc cells was supplemented with $1 \mathrm{nM} 17 \beta$-oestradiol (Merck, Darmstadt, Germany). ZR/HERc cells were derived from ZR-75-1 cells following introduction of human EGFR complementary DNA (Ullrich et al., 1984) utilizing a retroviral vector (Von Ruden \& Wagner, 1988) as previously described (van Agthoven et al., 1992). MDA/HEGO cells were derived from MDA-MB-231 cells as follows. Half confluent cultures of MDA-MB-23I cells were co-transfected with $10 \mu \mathrm{g}$ of the expression vector $\mathrm{HEGO}$ containing human ER complementary DNA (Tora et al., 1989) and $1 \mu \mathrm{g}$ pLN (Miller \& Rosman, 1989), expression vector for the neomycin resistance gene by cationic liposomes (Lipofectin
Reagent, Gibco BRL). Colonies surviving $1 \mathrm{mg} \mathrm{ml}^{-1}$ of the antibiotic G 418 sulphate (Sigma St Louis, MO, USA) and carrying the intact human ER CDNA were expanded to stable cell lines. The cells were harvested using $0.04 \%$ EDTA. Aliquots were made immediately after harvesting, one consisting of a 50:50 mixture of the MCF-7 and A431 cells. These were then immediately centrifuged at 1000 r.p.m. for $4 \mathrm{~min}$. The samples were resuspended in $1 \mathrm{ml} 0.01 \mathrm{M}$ phosphatebuffered saline (PBS) and centrifuged on a Jouan Microfuge (Hema-C) for one min. Immediately after removal of the supernatant the samples were snap-frozen to $-70^{\circ} \mathrm{C}$ in dry ice. The frozen pellets were placed in individual flexible plastic moulds that contained a semi-viscous freezing compound (OCT, Miles Laboratories, Naperville, Ill.) and snap frozen to $-70^{\circ} \mathrm{C}$ in dry ice. Five $\mu \mathrm{m}$-thick cryostat sections were cut the following day and thaw-mounted onto glass slides coated with poly-L-lysine tissue adhesive and immediately underwent the fixation procedures for the subsequent assays. All the samples were subjected to single immunocytochemical assays for ER and EGFR and the dual immunocytochemical assay for both antigens.

\section{Oestrogen receptor (ER)}

Cryostat sections were fixed in $3.7 \%$ formaldehyde-PBS $(\mathrm{pH}$ 7.2) for $15 \mathrm{~min}$ at room temperature, washed twice for $5 \mathrm{~min}$ in PBS, fixed at $-20^{\circ} \mathrm{C}$ in absolute methanol for $6 \mathrm{~min}$ followed by fixation in acetone at $-20^{\circ} \mathrm{C}$ for $3 \mathrm{~min}$ followed by two 5 -min washes in PBS. The sections were then stained. The reagents used for staining were obtained in kit form (ER-ICA Monoclonal, Abbott Laboratories, North Chicago, Ill.). The slides were initially incubated with blocking normal goat serum (NGS, $15 \mathrm{~min}$ ). Excess serum was removed and the subsequent staining procedure involved sequential incubations, with intervening PBS washes $(2 \times 5 \mathrm{~min})$, with rat monoclonal anti-ER or control normal rat IgG (30 min), bridging goat anti-rat IgG (30 min), rat peroxidase-antiperoxidase complex (30 min) and diaminobenzidine (DAB)-hydrogen peroxide $\left(\mathrm{H}_{2} \mathrm{O}_{2}\right)$ chromogen substrate $(6 \mathrm{~min})$. The slides were then rinsed in deionized water $(2 \times 5 \mathrm{~min})$ followed by incubation with $0.5 \%$ $\mathrm{CuSO}_{4}(2 \mathrm{~min})$ and were then washed in deionized water $(2 \times 5 \mathrm{~min})$, counterstained with $1 \%$ aqueous methyl green ( $5 \mathrm{~min}$ ), rinsed again in de-ionized water $(1 \mathrm{~min})$, dehydrated in graded ethanols $(50,70,90,100 \%)$, air-dried for $1 \mathrm{~h}$, cleared in xylene and cover-slips were applied using a xylene-soluble mountant.

\section{Epidermal growth factor receptor (EGFR)}

Cryostat sections were air-dried for $1 \mathrm{~h}$ prior to storage in a sealed box at $-70^{\circ} \mathrm{C}$ for $\mathrm{I}$ day prior to assay. The slides were rehydrated in PBS followed by fixation in 50:50 v/V chloroform-acetone at $4^{\circ} \mathrm{C}$ (10 min) followed by washing in PBS $(2 \times 5 \mathrm{~min})$. The sections were then incubated with $10 \%$ normal goat serum in PBS to block non-specific antibody binding (10 min). Excess serum was removed and mouse monoclonal primary anti-EGFR antibody (EGFRI, Amersham International, UK) or a control mouse anti-sheep erythrocyte antibody (MASE, Sera-Lab, UK) was added ( $60 \mathrm{~min}$ ). Both were added at $I \mu \mathrm{g} \mathrm{ml}^{-1}$ in $10 \%$ normal goat serum and $5 \%$ normal human serum. The control antibody being added to parallel sections of each specimen. Following the primary incubation the slides were washed in PBS $(3 \times 5 \mathrm{~min})$ followed by incubation with rabbit anti-mouse peroxidase-conjugated 
antiserum (Dakopatts, UK) at I:50 dilution in PBS containing final concentrations of 10\% normal goat serum and $5 \%$ normal human serum $(30 \mathrm{~min})$. The slides were then washed in PBS $(3 \times 5 \mathrm{~min})$ and immunoreactivity revealed by incubation with 3-amino-9-ethylcarbazole (AEC) plus $\mathrm{H}_{2} \mathrm{O}_{2}$ obtained in kit form (Immustain, DPC, Oxfordshire) for $10 \mathrm{~min}$. The sections were then washed in tap water $(2 \times 5 \mathrm{~min})$, counterstained with $1 \%$ aqueous methyl green ( $5 \mathrm{~min}$ ), washed again in deionized water (I min) and immediately coverslipped using Aquamount (Gurr, Poole, England).

\section{Dual immunocytochemical assay}

Various fixation procedures were attempted to establish which would retain good staining characteristics for both assays. These included:

(1) Acetone at room temperature $(20 \mathrm{~min})$

(2) $5 \%$ formaldehyde in PBS at room temperature (10 min)

(3) $100 \%$ ethanol at room temperature (10 $\mathrm{min}$ )

(4) $50: 50$ chloroform:acetone at $4{ }^{\circ} \mathrm{C}$ (10 min)

(5) ER immunocytochemical assay fixation procedure.

Of these, the ER-immunocytochemical assay fixation procedure was the only method which retained the histological structure of the tissue and good immunocytochemical staining characteristics for both ER (brown nuclear staining without cytoplasmic leaking) and EGFR (red membrane staining often accompanied by cytoplasmic staining). Consequently this procedure was adopted for this study. The slides then underwent the sequential steps used in the single ER assay until the incubation with $\mathrm{DAB}-\mathrm{H}_{2} \mathrm{O}_{2}$ which was applied for $10 \mathrm{~min}$. This extended incubation period achieved maximal colour production and was followed by washing in deionized water $(2 \times 5 \mathrm{~min})$ and then incubating with $0.5 \% \mathrm{CuSO}_{4}(2 \mathrm{~min})$. Following washing in deionized water $(5 \mathrm{~min})$ and PBS ( $5 \mathrm{~min})$, the sections were blocked using $20 \%$ normal goat serum and 10\% normal human serum in PBS ( $30 \mathrm{~min})$.

Significant changes were made to the original EGFRimmunocytochemical assay which ensured minimal crossreactivity of antisera and maximal specificity of reaction. After removal of excess serum, EGFRI at $1 \mu \mathrm{g} \mathrm{ml}^{-1}$ with $10 \%$ normal goat serum and $5 \%$ normal human serum in PBS was added to the test slides and mouse antisheep erythrocyte antibody (MASE), at a similar concentration, was added to the control slides (30 min). The EGFRI had been pre-incubated with three volumes of normal human serum and the MASE with two volumes of normal human serum for $30 \mathrm{~min}$ prior to final dilutions. The sections were then washed in PBS $(3 \times 5 \mathrm{~min})$ prior to adding the rabbit anti-mouse peroxidase-conjugated antiserum at 1:100 dilution in PBS with 10\% normal goat serum and $5 \%$ normal human serum $(30 \mathrm{~min})$. The rabbit anti-mouse peroxidase-conjugated antiserum had also been pre-incubated with three volumes of normal human serum for $30 \mathrm{~min}$ prior to final dilution. The remaining steps were as in the EGFR single immunocytochemical assay.

\section{Assessment and scoring}

The sections were examined using an Olympus $\mathrm{BH} 2$ light microscope with a dual viewing attachment by two observers ( $A S$ and $R M$ ) and scored according to the intensity of staining and the proportion of cells stained. For ER, scores 0 to 3 were allocated as $0=$ no staining, $1=$ weak nuclear staining,
$2=$ moderate nuclear staining and $3=$ strong nuclear staining. For EGFR, scores 0 to 3 were allocated as $0=$ no staining, $1=$ faint cytoplasmic reactivity, $2=$ distinct cytoplasmic or weak membrane reactivity, $3=$ strong membrane reactivity. The percentage of cells stained was estimated for each category. The final percentage receptor positivity was calculated by combining the values of all cells displaying any reactivity for that particular receptor $(1+2+3)$.

\section{Results}

\section{MCF-7 cells}

Brown nuclear ER staining was immunolocalized in $30 \%$ of MCF-7 cells by the single ER immunocytochemical assay. There was marked heterogeneity within this group with 15,10 and $5 \%$ of cells showing staining intensity of 1 to 3 respectively. The results were consistent between flasks as well as in serial cross-section examination. No EGFR staining was seen following the single EGFR immunocytochemical assay. The dual immunocytochemical assay also revealed 30\% ER staining with no EGFR staining. Again, the ER staining was heterogeneous, with the relative proportions being $1=5 \%, 2=10 \%$ and $3=15 \%$. The increased ER staining intensity is attributable to the increased DAB incubation period. There was no staining in the control slides.

\section{A431 cells}

Red cellular membrane EGFR staining was seen in 100\% of A431 cells. There was little heterogeneity of staining intensity with all cells displaying strong membrane reactivity. As with the $\mathrm{MCF}-7$ cells, the results were reproducible between flasks and in serial cross-section examination. No ER staining was seen following the single ER assay. The double assay gave identical results to the single assays in all the cells. There was no staining in the control slides.

\section{Mixture of MCF-7 and A431 cells}

$10 \%$ of tumour cells in the mixture were immuno-stained by the single ER assay procedure and displayed heterogeneity in staining intensity ( $1=5 \%, 2=3 \%, 3=2 \%$; $70 \%$ of the mixed cells displayed strong EGFR staining following the single EGFR assay. The discrepancy between the number of cells mixed and the relative proportions found in the frozen sections was attributed to differential centrifugation rates of the two types of cell as serial cross-section examination revealed increasing numbers of MCF-7 cells with a concomitant decrease in the A431 cell population. Three staining patterns were seen in the mixture following the dual immunocytochemical assay. Some $10 \%$ of the cells displayed brown nuclear staining alone without any leaking into the cytoplasm (ER +/EGFR - or MCF-7 cells) comparable to the single ER assay. Heterogeneity was again apparent with the relative proportions being $1=2 \%, 2=3 \%$ and $3=5 \%$. Some $70 \%$ of the cells displayed strong red 
membrane-associated staining alone (ER-/EGFR+ A431 cells) comparable to the EGFR-assay. Some $20 \%$ of the cells did not stain (ER-/EGFR - MCF-7 cells). The three groups were readily identified due to the colour difference and sites of staining. Control slides revealed no staining.

\section{ZR-75-I cells}

ER staining was immunolocalized in $60 \%$ of ZR-75-I cells by the ER immunocytochemical assay. Again, marked heterogeneity was present, with the relative proportions being $1=15 \%, 2=30 \%$ and $3=15 \%$. No EGFR staining was observed following the single EGFR assay. The dual assay gave similar results to the single assays with no EGFR staining and $60 \%$ ER staining. The heterogeneous ER staining pattern was identical to that obtained with the single ER assay. There was no staining in control slides.

\section{$\mathrm{ZR} /$ HERc cells}

$60 \%$ of $Z R / H E R c$ cells displayed brown nuclear staining following the single ER assay in a heterogeneous pattern similar to the ZR-75-1 cells. In addition, $80 \%$ of the cells displayed red membrane-associated and cytoplasmic staining following the single EGFR assay. This was uniform, being weak to moderate in intensity. The double assay on the ZR/HERc cells gave three staining patterns. Some $20 \%$ of the cells displayed brown nuclear staining alone (ER+/EGFR-), $40 \%$ displayed weak to moderate red membrane-associated and cytoplasmic staining alone (ER-/EGFR+), and $40 \%$ displayed both weak to moderate EGFR staining and variable ER staining. The intensity of ER staining was not related to the intensity of EGFR staining, which was uniform in these $\mathrm{ER}+/ \mathrm{EGFR}+$ cells. There was no staining in the control slides.

\section{MDA-MB-231 cells}

$100 \%$ of the MDA-MB-23I cells displayed strong uniform EGFR reactivity following the single EGFR assay. No ER staining was immunolocalized by the ER assay. The double procedure again gave similar results to the single assays and there was no staining in the control slides.

\section{MDA/HEGO}

$10 \%$ of MDA/HEGO cells displayed ER staining in a heterogeneous manner following the ER assay ( $1=3 \%$, $2=4 \%, 3=3 \%$ ). Some $100 \%$ displayed strong EGFR reactivity uniformly after the single EGFR procedure. The dual assay revealed two staining patterns. Some 90\% displayed strong EGFR staining alone and 10\% displayed strong EGFR staining and variable ER staining ( $I=2 \%, 2=3 \%$ and $3=5 \%$ ). Again, no relationship between the intensity of ER and EGFR staining was apparent. There was no staining in the control slides.

\section{Discussion}

The current study has shown that it is possible to perform a dual immunocytochemical assay for ER and EGFR on a series of cell culture lines using two sequential indirect immunoperoxidase systems on a single $5-\mu \mathrm{m}$ frozen section sample. Our results show that the double immunocytochemical assay is capable of demonstrating all four phenotypes with respect to ER and EGFR $($ ER $+/$ EGFR -,$\quad$ ER $-/$ EGFR -,$\quad E R-/ E G F R+$ and $E R+/ E G F R+$ ) with levels of staining comparable to the single assays in these cell lines.

Results derived from MCF-7 and ZR-75-I cells show these cell lines to be ER-positive and fail to demonstrate any EGFR reactivity using either the single or dual assay systems. Scatchard analysis also failed to identify EGFR on these ZR-75-1 cells (van Agthoven et al., 1992). Interestingly, the percentage of cells which are ERpositive and their staining intensity is variable with approximately $70 \%$ of MCF-7 cells and $40 \%$ of ZR-75-I cells being detected as ER-negative. The observation that only $30 \%$ of MCF-7 cells display ER-positivity in a heterogeneous manner is in concordance with previous immunocytochemical studies which have demonstrated that the staining intensity and proportion of cells displaying ER-positivity increases in culture as the cells approach confluence (Bouzubar, 1991). The MCF-7 cells used in the present study were harvested during exponential growth explaining the low positivity value. Indeed, the presence of the ER-/EGFR - phenotype is frequently seen in both benign and malignant breast tissue which has been categorized as being ER-positive (Walker $e t$ al., 1991). It has been suggested that these double-negative cells represent a resting cell population (Nicholson, 1992).

Our findings of strong EGFR positivity in A431 and MDA-MB-231 cells using both the single EGFR and dual assays are in agreement with previous studies (WynfordThomas et al., 1986; Lee et al., 1990). The stable transfection of ER-positive ZR-75-I cells with human EGFR cDNA and EGFR-positive MDA-MB-23I cells with human ER CDNA has produced phenotypes which have been shown to express both ER and EGFR using enzyme immunoassays (van Agthoven et al., 1992) (data not shown). Such cells are now shown by the dual-immunocytochemical assay to co-express the two receptor proteins. Even with the transfected cell populations, neither ER nor EGFR are expressed uniformly. This is possibly explained by cell cycle regulation of the ectopically expressed genes or instability of the transfected cell lines. Alternatively or in combination, expression of these genes may be at a threshold level of detection and thus give false negative results.

The introduction of the EGFR CDNA into ER-positive ZR-75-I cells results in an altered differentiation state and the development of endocrine independence (van Agthoven et al., 1992), while introducing the ER cDNA 
into EGFR-positive MDA-MB-231 cells reduces cell proliferation rates and invasiveness in the presence of oestradiol but not in the presence of anti-oestrogens (Garcia et al., 1992). These results would suggest that factors other than ER are involved in the progression to endocrine insensitivity and suggest a possible role for EGFR. Application of the dual assay to human breast cancer specimens should now allow us to study the inverse relationship between ER and EGFR at the individual cellular level. It may also allow us to further study the transition from hormone-sensitive to hormone-insensitive disease. These investigations are currently in progress.

\section{References}

BEVILACQUA, P., GASPARINI, C., DAL-FIOR, S. \& CORRODI, G. (1990) Immunocytochemical determination of epidermal growth factor receptor with monoclonal EGFR1 antibody in primary breast cancer patients. Oncology 47, 313-7.

BILOUS, M., MILLIKEN, J. \& MATHIJS, J.-M. (1992) Immunocyto-chemistry and in situ hybridisation of epidermal growth factor receptor and relation to prognostic factors in breast cancer. Eur. J. Cancer 28, 1033-7.

BOUZUBAR, N. F. H. (1991) Studies of hormone and antihormone action in early breast cancers using immunocytochemical techniques. PhD thesis, University of Cardiff.

COHEN, S., USHIRO, H., STOSCHECK, C. \& CHINKERS, M. (1982) A native 170000 epidermal growth factor receptor-kinase complex from shed plasma membrane vesicles. J. Biol. Chem. 257, 1523-31.

DOWNWARD, J., PARKER, P. \& WATERFIELD, M. D. (1984) Autophosphorylation sites on the epidermal growth factor receptor. Nature 311, 483-5.

GARCIA, M., DEROCQ, D., FREISS, G. \& ROCHEFORT, H. (1992) Activation of estrogen receptor transfected into a receptornegative breast cancer cell line decreases the metastatic and invasive potential of the cells. Proc. Natl Acad. Sci. USA 89, II 538-42.

KING, W. J. \& GREENE, G. L. (1984) Monoclonal antibodies localize oestrogen receptor in the nuclei of target cells. Nature 307, $745-7$.

LEE, C. S. L., HALL, R. E., ALEXANDER, I. E., KOGA, M., SHINE, J. \& SUTHERLAND, R. L. (1990) Inverse relationship between estrogen receptor and epidermal growth factor receptor mRNA levels in human breast cancer cell lines. Growth Factors 3, 97-103.

LEWIS, S., LOCKER, A., TODD, J. H., BELL, J. A., NICHOLSON, R., ELSTON, C. W., BLAMEY, R. W. \& ELLIS, I. O. (1990) Expression of epidermal growth factor receptor in breast carcinoma. $J$. Clin. Pathol. 43, 385-89.

MCCLELLAND, R. J., BERGER, U., MILLER, L. S., POWLES, T. J. \& COOMBES, R. C. (1986) Immunocy tochemical assay for estrogen receptor in patients with breast cancer: relationship to a biochemical assay and to outcome of therapy. J. Clin. Oncol. 4, $1171-76$.

MILLER, A. D. \& ROSMAN, G. J. (1989) Improved retroviral vectors for gene transfer and expression. BioTechniques 7, 980-2, 984-6, 989-90.

NICHOLSON, R. I. (1992) Why ER level may not reflect endocrine responsiveness in breast cancer. Rev. Endocrine-Related Can cer 40, 25-8.
NICHOLSON, R. I., COLIN, P., FRANCIS, A. B., KESHRA, R., FINLAY, P., WILLIAMS, M., ELSTON, C. W., BLAMEY, R. W. \& GRIFFITHS, K. (1986) Evaluation of an enzyme immunoassay for estrogen receptors in human breast cancers. Cancer Res. (suppl.) 46, $4299 \mathrm{~s}-302 \mathrm{~s}$.

NICHOLSON, S., WRIGHT, C., SAINSBURY, J. R. C., HALCROW, P., KELLY, P., ANGUS, B., FARNDON, J. R. \& HARRIS, A. L. (1990) Epidermal growth factor receptor (EgfR) as a marker for poor prognosis in node-negative breast cancer patients; neu and tamoxifen failure. J. Steroid Biochem. Mol. Biol. 37, 811-4.

OSBORNE, C. K., YOCHMOWITZ, M. G., MCGUIRE, W. A. \& MCGUIRE, W. L. (I980) The value of estrogen and progesterone receptors in the treatment of breast cancer. Cancer 46 , 2884-8.

SAINSBURY, J. R. C., FARNDON, J. R., SHERBET, G. V. \& HARRIS, A. L. (1985) Epidermal growth factor receptors and oestrogen receptors in human breast cancer. Lancet $i, 364-6$.

SAINSBURY, J. R. C., FARNDON, J. R., NEEDHAM, G. K., MALCOLM, A. J. \& HARRIS, A. L. (1987) Epidermal growth factor receptor status as predictor of early recurrence of and death from breast cancer. Lancet i, 1398-402.

TOI, M., HAMADA, Y., NAKAMURA, T., MUKAIDA, H., SUEHIRO, S. WADA, T., TOGE, T., NIMOTO, M. \& HATTORI, T. (1989) Immunocytochemical and biochemical analysis of epidermal growth factor receptor expression in human breast cancer tissues: relationship to estrogen receptor and lymphatic invasion. Int. J. Cancer 43, 220-5.

TORA, L., MULLICK, A., METZGER, D., PONGLIKITMONGKOL, M., PARK, I. \& CHAMBON, P. (1989) The cloned human oestrogen receptor contains a mutation which alters its hormone binding properties. EMBO J. 8, 1981-6.

ULLRICH, A., COUSSENS, L., HAYFLICK, J. S., DULL, T. J., GRAY, A., TAM, A. W., LEE, J., YARDEN, Y., LIBERMANN, T. A., SCHLESSINGER, J. DOWNWARD, J., MAYES, E. L. V., WHITTLE, N., WATERFIELD, M. D. \& SEEBURG, P. H. (1984) Human epidermal growth factor receptor cDNA sequence and aberrant expression of the amplified gene in A431 epidermoid carcinoma cells. Nature 309, 418-25.

VAN AGTHOVEN, T., VAN AGTHOVEN, T. L. A., PORTENGEN, $\mathrm{H}$, FOEKENS, J. A. \& DORSSERS, L. C. J. (1992) Ectopic expression of epidermal growth factor receptors induces hormone independence in ZR-75-1 human breast cancer cells. Cancer Res. 52, 5082-7.

VON RUDEN, T. \& WAGNER, E. F. (1988) Expression of functional human EGF receptor on murine bone marrow cells. $E M B O$ J. 7, 2749-56.

WALKER, K. J., BOUZUBAR, N., ROBERTSON, J., ELLIS, I. O., ELSTON, C. W., BLAMEY, R. W., WILSON, D. W., GRIFFITHS, K. \& NICHOLSON, R. I. (1988) Immunocytochemical localization of estrogen receptor in human breast tissue. Cancer Res. 48, 6517-22.

WALKER, K. J., PRICE-THOMAS, M. J., CANDLISH, W. \& NICHOLSON, R. I. (1991) Influence of the antioestrogen tamoxifen on normal breast tissue. Br. J. Cancer 64, 764-8.

WATERFIELD, M. D., MAYES, E. L. B., STROOBANT, P., BENNETT, P. L. P., YOUNG, S., GOODFELLOW, P. N., BANTING, G. B. \& OZANNE, B. (1982) A monoclonal antibody to the human epidermal growth factor receptor. J. Cell Biochem. 20, 149-61.

WYNFORD-THOMAS, D., JASANI, B. \& NEWMAN, G. R. (1986) Immunohistochemical localization of cell surface receptors using a novel method permitting simple, rapid and reliable LM/EM correlation. Histochem. J. 18, 387-96. 